\title{
The triangle of inequality in dental services: arguments for a new conceptual framework
}

\author{
Arash Ghanbarzadegan ${ }^{1}$, Peivand Bastani ${ }^{2,3^{*}} \mathbb{D}$, Madhan Balasubramanian ${ }^{4,5}$, David Brennan ${ }^{1}$ and \\ Lisa Jamieson ${ }^{1}$
}

\begin{abstract}
This short communication paper aimed to compile the main determinants of inequality in dental services by distinguishing between access, utilisation, and provision of dental services. Recent findings integrated, and a dedicated conceptual framework entitled "Triangle of inequality in dental services" has been suggested. These can contribute a rich knowledge in this area and open a new window for policymakers and researchers to seek applied interventions to decrease inequality and improve access and utilisation in communities. This paper aims to synthesise the available evidence and add value to the scope. It highlights a dedicated concept for inequality in dental services beyond other areas of public health.
\end{abstract}

Keywords: Access, Utilisation, Provision, Oral and dental health

\section{Background}

Oral health is integral to general health and wellbeing and is considered a global public health concern, particularly in many low- and middle-income countries (LMICs) [1]. Considering that oral disease is still a major public health burden worldwide with the greater global burden on the deprived and poor population [2], integrating oral health to general health globally can be among health policymakers' interests [3]. Moreover, the direct and lasting impact of oral health on general health makes the policymakers prioritise access to dental services by the whole community at the top of agenda-setting.

Lack of integration between oral health and global public health with a population health approach can lead to many health concerns. Inequality in providing and utilising dental services can worsen these concerns. According to the evidence, many social, economic, cultural and environmental determinants at the macro and micro

\footnotetext{
*Correspondence: peivandbastani@hotmail.com

${ }^{2}$ Health Human Resources Research Centre, School of Health

Management and Medical Informatics, Shiraz University of Medical Sciences, Shiraz, Iran

Full list of author information is available at the end of the article
}

levels along with meso elements related to insurance, providers and policies and practices are among the determinants that lead to inequality in the area of oral health in LMICs [4]. Inequality in utilisation of dental services even in developed countries is severe and influenced by many factors. Individual, social, economic, and cultural determinants are the main determinants of inequality in utilisation of dental services. In addition to this, health policies and availability of services are indicators of provision of dental services that lead to inequalities in such services [5]. For instance, changes in oral health policies during the COVID-19 pandemic with greater emphasis on providing emergency services at the peak of the outbreak, along with restricting non-emergency dental services, have significant impacts on the population's access and utilisation of dental services [6].

Evidence emphasises the necessity of policymakers' particular attention to appropriate access to dental services to decrease inequalities and improve the oral health of a given population. Despite identifying the above determinants, the nature of dental services is uniquely different from public health services. In other words, although oral health should be considered as part original author(s) and the source, provide a link to the Creative Commons licence, and indicate if changes were made. The images or other third party material in this article are included in the article's Creative Commons licence, unless indicated otherwise in a credit line to the material. If material is not included in the article's Creative Commons licence and your intended use is not permitted by statutory regulation or exceeds the permitted use, you will need to obtain permission directly from the copyright holder. To view a copy of this licence, visit http://creativecommons.org/licenses/by/4.0/. The Creative Commons Public Domain Dedication waiver (http://creativeco mmons.org/publicdomain/zero/1.0/) applies to the data made available in this article, unless otherwise stated in a credit line to the data. 
of global public health, because of the different nature of oral health and in particular dental services, inequality in dental services can be intensified and should be regarded as a serious concern. Therefore, it is essential that policymakers focus on a dedicated model to better understand inequality mechanisms in dental services. Some reasons can justify the necessity of such a model.

In the dental literature, access, utilisation and provision of dental services are terms often used interchangeably. However, to better address the determinants of inequality in dental services, it is essential to distinguish between these concepts. In health sciences, service utilisation is defined as the individual's preventive or curative service use; service provision deals with the process of providing services according to the available resources (human resources, physical capital and consumables) $[5,7]$. Access to health services is the timely use of these services to achieve the best health outcomes both at individual and population levels [8].

Dental services are uniquely different from other public health and primary health care services. Dental services often have higher costs with limited comprehensive insurance coverage, so the out-of-pocket payments are relatively high for dental services. This creates a model of care that favours emergency dental visits. A cycle of delayed referrals, specialised needs and higher cost of these specialised services increases the gap in utilisation and therefore leads to a worsening oral health status at the population level [5].

The impact of community diversities in cultural, economic, social and health literacy on the utilisation of dental services should not be under-estimated [9]. Although this is a global issue, it should be formulated and customised according to different contexts, policymakers motivations, priorities and severity of the issue for any context.

A conceptual model is helpful in highlighting the principal elements and strategic points that better facilitate timely and appropriate dental service provision. Such a model should integrate different concepts of access, utilisation and provision of dental services. It clarifies that more appropriate provision of quality services affects higher access and broader utilisation of the services. In addition, different aspects of access, such as physical, geographical, cultural and financial aspects, along with the acceptability of the services [10], lead to higher dental service utilisation, and as a result, a reduction in inequalities in dental services.

\section{Conceptual framework}

Ghanbarzadegan et al. (2021) previously introduced the "Triangle of Inequality" in dental services concept (Fig. 1) [5, 10]. As illustrated in Fig. 1, provision of dental services in the top of this hierarchy influences access

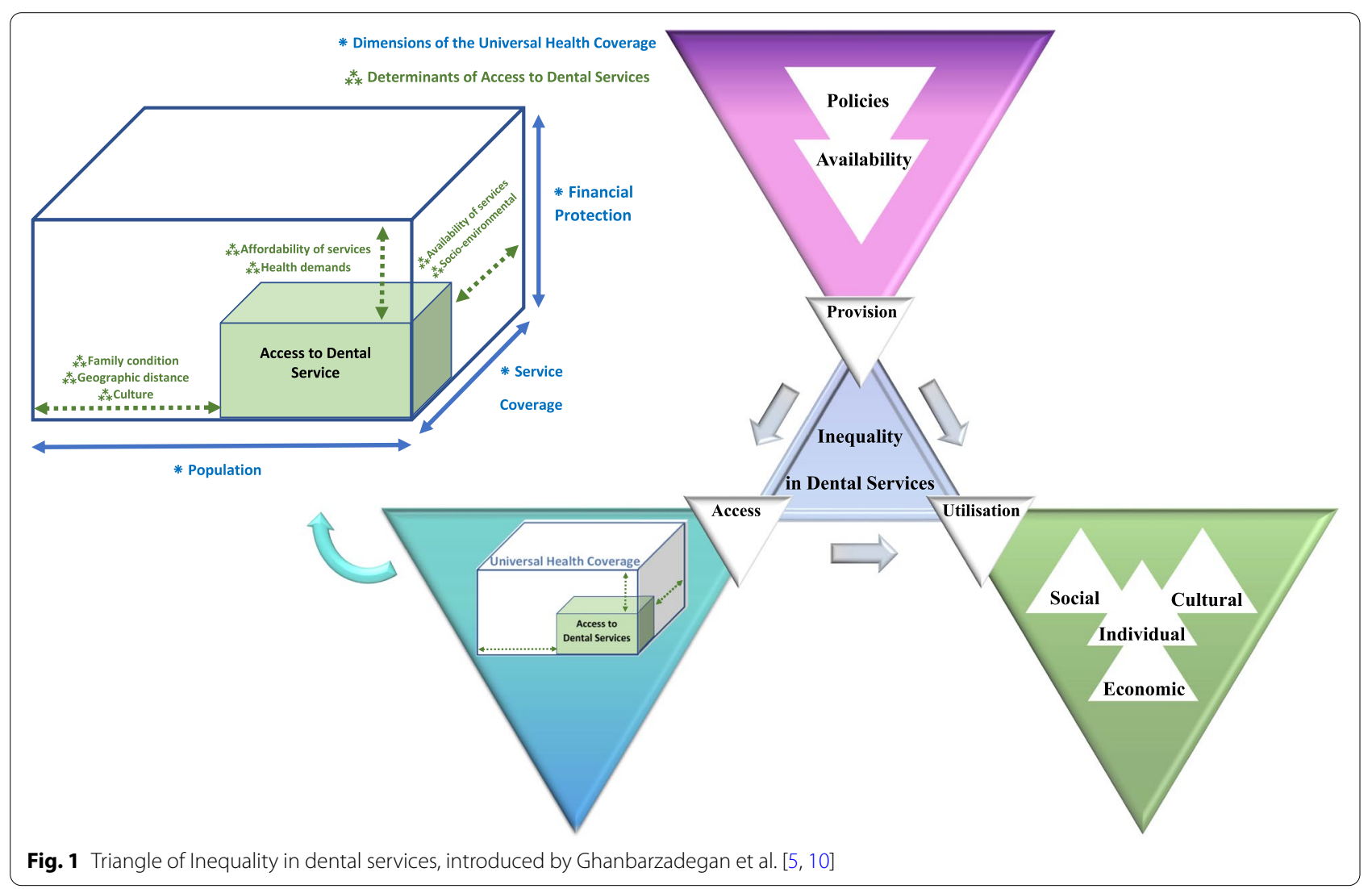


and utilisation of services. In this framework, determinants of access to dental services are aligned with the Universal Health Coverage (UHC) dimensions, with the key to increasing access to dental services being to reduce the existing gap in dental services universal coverage. Each small triangle is also directed to another triangle to show how these determinants are intertwined. For example, in the framework of service provision, oral health policies influence the availability of services and these would define access to dental services from different perspectives such as availability, affordability or even geographic access. Providing need-based dental services at the affordable and acceptable prices improves the access to these services. Simultaneously, the provision of oral and dental services is affected by the availability of the services and oral and dental health policies. According to the triangle, if the services are provided and are accessible to the population, inequality will decrease only by developing service utilisation. This third item will be fulfilled considering the individual, cultural, social and economic determinants of the population.

Policymakers may move to a trade-off among these determinants according to the priorities, community's conditions, financial capability (e.g., GDP per capita allocated specifically for dental health provision), basic health benefit packages and insurance coverage of dental services. Also, in the access aspect of the model, the supply chain, which indicates the dental service providers, availability of human resources and equipment, can be effective along with the demand side of the population and its demographic characteristics as well other determinants of utilisation, provision and access to services previously discussed.

\section{Conclusion}

In conclusion, due to the unique nature of dental services and their differences with other health services, the lack of clear definitions of various dimensions of inequality in services and inappropriate and mistakenly interchangeable use of access, utilisation and provision concepts, there is a need to redefine these dimensions in dental services. The "triangle of inequality" as a conceptual model in dental services may assist in ameliorating inequalities in dental services by clarifying the concepts mentioned above and their determinants.

\section{Abbreviation}

LMIC: Low- and middle-income countries.
Acknowledgements

Not applicable.

Authors' contributions

AG and PB have designed and drafted the study, MB and DB have contributed in developing the conceptual framework and $L J$ has supervised the whole work. All the authors read and approved the final manuscript.

Funding

There was no funding

Availability of data and materials

Are available from the corresponding author on reasonable request.

\section{Declarations}

Ethics approval and consent to participate

Not applicable.

Consent for publication

Not applicable.

Competing interests

There were no competing interests.

\section{Author details}

${ }^{1}$ Australian Research Centre for Population Oral Health (ARCPOH), Adelaide Dental School, The University of Adelaide, Adelaide, SA, Australia. ${ }^{2}$ Health Human Resources Research Centre, School of Health Management and Medical Informatics, Shiraz University of Medical Sciences, Shiraz, Iran. ${ }^{3}$ School of Dentistry, Faculty of Health and Behavioural Sciences, University of Queensland, Herston, Queensland, Australia. ${ }^{4}$ Health Care Management, College of Business, Government and Law, Flinders University, Bedford Park, SA, Australia. ${ }^{5}$ Menzies Centre for Health Policy and Economics, School of Public Health, Faculty of Medicine and Health, The University of Sydney, Sydney, NSW, Australia.

Received: 24 December 2021 Accepted: 8 February 2022

Published online: 18 February 2022

\section{References}

1. Peres MA, Macpherson LM, Weyant RJ, Daly B, Venturelli R, Mathur $M R$, et al. Oral diseases: a global public health challenge. Lancet. 2019;394(10194):249-60.

2. Petersen PE, Bourgeois D, Ogawa H, Estupinan-Day S, Ndiaye C. The global burden of oral diseases and risks to oral health. Bull World Health Organ. 2005;83:661-9.

3. Jin L, Lamster I, Greenspan J, Pitts N, Scully C, Warnakulasuriya S. Global burden of oral diseases: emerging concepts, management and interplay with systemic health. Oral Dis. 2016;22(7):609-19.

4. Bastani P, Mohammadpour M, Mehraliain G, Delavari S, Edirippulige S. What makes inequality in the area of dental and oral health in developing countries? A scoping review. Cost Effect Resour Allocation. 2021;19(1):1-12.

5. Ghanbarzadegan A, Bastani P, Luzzi L, Brennan D. Inequalities in utilization and provision of dental services: a scoping review. Syst Rev. 2021;10(1):1-11.

6. Jiang CM, Duangthip D, Auychai P, Chiba M, Folayan MO, Hamama HHH, et al. Changes in oral health policies and guidelines during the COVID-19 pandemic: University of British Columbia; 2021.

7. Carrasquillo O. Health care utilization. In: Gellman MD, Turner JR, editors. Encyclopedia of behavioral medicine. New York: Springer New York; 2013. p. 909-10. 
8. Gulliford M, Figueroa-Munoz J, Morgan M, Hughes D, Gibson B, Beech $R$, et al. What does'access to health care'mean? J Health Serv Res Policy. 2002;7(3):186-8

9. Evans DB, Hsu J, Boerma T. Universal health coverage and universal access. Bulletin of the World Health Organization. 2013;91:546-A.

10. Ghanbarzadegan A, Balasubramanian M, Luzzi L, Brennan D, Bastani P. Inequality in dental services: a scoping review on the role of access toward achieving universal health coverage in oral health. BMC Oral Health. 2021;21(1):1-11.

\section{Publisher's Note}

Springer Nature remains neutral with regard to jurisdictional claims in published maps and institutional affiliations.

- fast, convenient online submission

- thorough peer review by experienced researchers in your field

- rapid publication on acceptance

- support for research data, including large and complex data types

- gold Open Access which fosters wider collaboration and increased citations

- maximum visibility for your research: over $100 \mathrm{M}$ website views per year

At BMC, research is always in progress.

Learn more biomedcentral.com/submissions 